\title{
Unintended Consequences of Unemployment Insurance: Evidence from Stricter Eligibility Criteria in Brazil
}

Cristiano C. Carvalho

RAPHAEl CoRbI

RENATA NARITA 
DEPARTMENT OF ECONOMICS, FEA-USP

WORKING PAPER № 2017-16

\title{
Unintended Consequences of Unemployment Insurance: Evidence from Stricter Eligibility Criteria in Brazil
}

\author{
Cristiano C. Carvalho (cristianocostacarvalho@gmail.com) \\ Raphael Corbi (rcorbi@usp.br) \\ Renata Narita (rnarita@usp.br)
}

\begin{abstract}
:
This paper investigates the impact of changes in the eligibility criteria of unemploy- ment benefits (UI) on layoffs in Brazil. We exploit exogenous variation introduced by a reform in the UI system in 2015. Our difference-in-differences estimates show that UI accounts for $11-13 \%$ of the average dismissal rates of eligible workers. Our results are consistent with workers having the incentive to strategically induce their dismissals in order to collect UI benefits
\end{abstract}

Keywords: unemployment insurance; labor legislation; job turnover; layoffs.

JEL Codes: J63; J64; J65; J46. 


\title{
Unintended Consequences of Unemployment Insurance: Evidence from Stricter Eligibility Criteria in Brazil*
}

\author{
Cristiano C. Carvalho ${ }^{\dagger} \quad$ Raphael Corbi ${ }^{\dagger \dagger} \quad$ Renata Narita ${ }^{\ddagger \ddagger}$
}

First version: October, 2015

This version: July, 2017

\begin{abstract}
This paper investigates the impact of changes in the eligibility criteria of unemployment benefits (UI) on layoffs in Brazil. We exploit exogenous variation introduced by a reform in the UI system in 2015. Our difference-in-differences estimates show that UI accounts for $11-13 \%$ of the average dismissal rates of eligible workers. Our results are consistent with workers having the incentive to strategically induce their dismissals in order to collect UI benefits.
\end{abstract}

JEL Codes: J63, J64, J65, J46.

Keywords: unemployment insurance, labor legislation, job turnover, layoffs.

${ }^{*}$ We thank Hélio Zylberstajn, Gustavo Gonzaga, Carlos Henrique Corseuil as well as many seminar and conference participants for their valuable suggestions. We are also grateful to Fapesp, Capes and CNPq for their financial support.

†University of São Paulo (cristianocostacarvalho@usp.br).

${ }^{\dagger \dagger}$ University of São Paulo (rcorbi@usp.br).

${ }^{\ddagger}$ Corresponding author. University of São Paulo (rnarita@usp.br). 


\section{Introduction}

Unemployment insurance (UI) is a mechanism of consumption smoothing designed to cover displaced workers that has been largely adopted in both developed and developing countries. In Brazil, public expenditure with UI benefits reached over US\$ 10.1 billion and covered 8.4 million workers laid-off from a formal job in 2014. Despite the program economic relevance, we do not find many studies investigating its impacts on Brazilian labor market turnover ${ }^{1}$.

Most theoretical research on UI have focused on evaluating the properties of an optimal contract in the presence of moral hazard. As for the empirical work, most studies show how changes in level and potential UI duration distort the unemployment spell of eligible displaced workers. However, little attention has been given to the behavior of the non-eligible as well as of those individuals already employed. In particular, little is known about how the probability of being laid off responds to changes in the incentives provided by the UI system (Mortensen, 1977; Chetty and Finkelstein, 2013).

This paper exploits an exogenous change in the eligibility criteria for UI benefit to assess its causal effect on layoffs. Using a difference in differences approach, we find that the UI incentives accounts for $11-13 \%$ of total layoffs. Besides UI payments, Brazilian workers have extra incentives to induce their dismissals as they are also entitled to redundancy pay by law. ${ }^{2}$ In fact, job turnover is relatively high in Brazil despite its strict labor legislation. According to the World Bank (2002), one third of the labor force changes job every year. Some authors argue that unemployment subsidies such as UI are behind this pattern (Barros, Corseuil, and Foguel, 2000; Gonzaga, Maloney, and Mizala, 2003). Moreover, the informal sector accounts for a large share of the labor force and it is not easy to identify workers who simultaneously receive UI and are employed in the informal economy.

\footnotetext{
${ }^{1}$ Exceptions include Gerard and Gonzaga (2016) and Gerard, Rokkanen, and Rothe (2016) who evaluate the effect of receiving UI on the workers' return to formal jobs in Brazilian labor market.

${ }^{2}$ In addition, the Brazilian UI system is not experience-rated as in many other countries. Thus payroll tax rates do not depend on the employer's unemployment history.
} 


\section{Institutional Background}

Labor contracts in Brazil are regulated by the Consolidação das Leis de Trabalho (CLT) enacted in 1943 and the 1988 Federal Constitution. The labor code only covers registered workers and is considered strict. The minimum wage is relatively high (79\% of median wage in 2015) and workers are entitled to one-month-pay

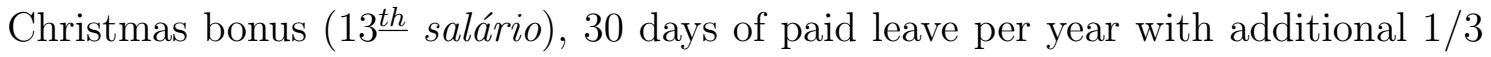
wage bonus, 120 days of maternity leave and $50 \%$ overtime premium for hours worked in excess 44 hours a week. Payroll taxes are compulsory and mainly include $20 \%$ for Social Security and $8 \%$ towards workers' seniority account (FGTS). Firing costs are also high. Employers must give workers a one-month advance notice, a redundancy fine of $40 \%$ of the amount deposited in their seniority account to the worker, and additional $10 \%$ to the government. ${ }^{3}$

Workers laid off without a justified reason from a private formal job are eligible to UI provided they have reached a minimum level of job tenure. UI potential duration depends on accumulated tenure across all registered jobs in the 36 months prior to the layoff. Workers are eligible for 3, 4 or 5 monthly paid benefits if they had respectively 6 to 11,12 to 23 , or more than 24 months of accumulated tenure including a one-month advance notice period. Benefit levels are based on the average wage of last three months and range from 1 to 1.7 minimum wages. Replacement rates are full at the bottom and decrease with wage. ${ }^{4}$ Workers cannot withdraw UI payments if reemployed. The benefit is canceled if his name appears in the CAGED, a monthly administrative data where employers report all formal admissions. However, it is not easy to identify workers reemployed in the informal sector while receiving UI benefits as enforcement is low.

The eligibility criteria for UI was modified by MP665 (Provisional Measure 665), enacted in December 30, 2014, and only enforced in February 28, 2015. ${ }^{5}$ By its nature, a Provisional Measure does not need prior discussions in Congress to be enacted. ${ }^{6}$ In July, 2015, MP665 was approved by Congress with some changes and

\footnotetext{
${ }^{3}$ Firms can avoid firing costs using fixed-term contracts that last less than or equal 3 months, but not recurrently for the same worker.

${ }^{4} 100 \%$ for workers who earn the minimum wage.

${ }^{5} \mathrm{MP}$ (Provisional Measure) is a mechanism enacted by the President to modify the legislation often with immediate effect. In MP665 case, the change took 60 days to be enforced. MP has the same power as a law but needs to pass in Congress within 120 days.

${ }^{6}$ The content of the reform was not anticipated. According to several media reports, President
} 
Figure 1: Changes in UI Eligibility According to Job Tenure

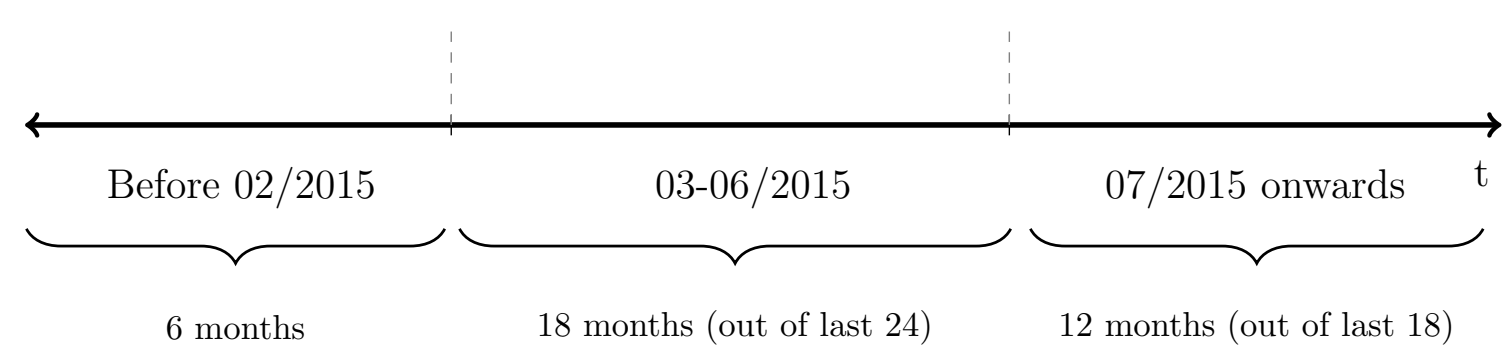

turned into Law 13.134.

Figure 1 shows the time-line of eligibility criteria changes introduced by MP665 and Law 13.134. Before MP665, workers were eligible to UI if they had worked continuously in the 6 months prior to layoffs. Since MP665 came into effect at the end of February, 2015, workers were required to have at least 18 months of accumulated tenure in the 24 months prior to layoff. ${ }^{7}$ With the approval of Law 13.134, the minimum tenure requirements became less strict than the ones set by MP665. According to Law 13.134, workers need to have at least 12 (instead of 18) months of cumulative tenure in the 18 (instead of 24) months prior to layoff. ${ }^{8}$

The UI reform was officially justified as an attempt to reduce the government budget deficit by cutting public spending. As workers may strategically induce layoffs in order to collect UI payments and find a job in the informal sector, it was also argued that the new rules would prevent frauds in UI program especially among low skilled workers, for whom UI benefits are relatively higher.

\section{$3 \quad$ Data and Empirical Strategy}

Our main source of labor market data is Relação Anual de Informações Sociais (RAIS). This is an employer-employee administrative dataset assembled yearly by the Brazilian Ministry of Labor. It is effectively a high-quality census of the

Dilma Rousseff, running for reelection, said she would not harm workers' rights. Ms Rousseff was re-elected at the end of October 2014.

${ }^{7}$ This only applies to workers accessing UI for the first time (approximately half of all UI applicants). For the second access it was required 12 months worked in the last 16 months, and for third or more accesses, 6 months of continuous employment prior to layoff as before.

${ }^{8}$ This applies for workers in their first access to UI. Workers in second access are required 9 months in the last 12 months, and for workers in third request or higher, it remained the same. 
Brazilian formal labor market that comprises detailed contractual information on 76.1 million registered workers and 3.9 million registered firms. Providing accurate information to RAIS is required for workers to receive in-work benefits and firms face fines for failing to report. Each observation represents an employment contract between a firm and a worker and contains information on monthly wage, age, gender, race, education level, sector, occupation, month of admission and separation, establishment size and location. Using this information, we are able to retroactively calculate individual monthly job tenure.

Our final dataset includes 31.7 million individual monthly observations and spans from January 2012 to December 2015. It is built by extracting a $10 \%$ random sample stratified by tenure and month out of the total pool of workers with openended contracts who work in private firms, earn non-zero wages, are at least 18 years old and are not on leave. ${ }^{9}$

Table 1: Eligibility Criteria and Sample Definition

\begin{tabular}{lcccc}
\hline Sample & $\begin{array}{c}\text { Job Tenure } \\
\text { (in months) }\end{array}$ & Before 02/2015 & 03/2015 to 06/2015 & Law n After $06 / 2015^{\text {MP65 }}$ \\
\hline Treated (1) & $6-7$ & Eligible & Non-eligible & Non-eligible \\
Control (1) & $4-5$ & Non-eligible & Non-eligible & Non-eligible \\
& & & & \\
Treated (2) & $13-17$ & Eligible & Non-eligible & Eligible \\
Control (2) & $18-22$ & Eligible & Eligible & Eligible \\
\hline
\end{tabular}

In our analysis we exploit two separate treatment events triggered by MP665 and Law 13.134 that affect two distinct sample of workers defined according to their job tenure, as reported in Table 1. Each sample is divided into treatment and control groups. Sample (1) includes workers with tenure of 4-5 months (control) and 6-7 (treated). ${ }^{10}$ The treated who were eligible for UI until 02/2015 became non-eligible with MP665 and remained so from then on. The control group are non-eligible throughout the period. Sample (2) comprises workers with tenure of 13-17 months (treated) and 18-22 (control). While the control group remains eligible over time, the treated were eligible for UI until 02/2015 and after 06/2015 but non-eligible in between. ${ }^{11}$

\footnotetext{
${ }^{9}$ Temporary workers are not eligible for UI. Employees in state-owned and mixed-ownership firms are rarely dismissed.

${ }^{10}$ We exclude workers in labor contracts with tenure less than or equal to 3 months as these are typically characterized by a fixed-term probation period as defined by law.

${ }^{11}$ We chose not to include workers with tenure of 5-6 and 17-18 months in the analysis as we do not observe the exact day of admission and separation. Since 15 days worked may qualify as one
} 
The richness of the variation introduced by these two institutional rules is twofold. First, the eligibility criteria modified by MP665 imply a change in status from eligible to non-eligible for two different set of individuals with lower and higher job tenure, samples (1) and (2) respectively. Second, Law 13.134 introduces a change in status in the opposite direction, namely from non-eligible to eligible for the treated in sample (2). ${ }^{12}$

Figure 2: Dismissal Rates According to Job Tenure
(a) MP665
(b) Law 13.134
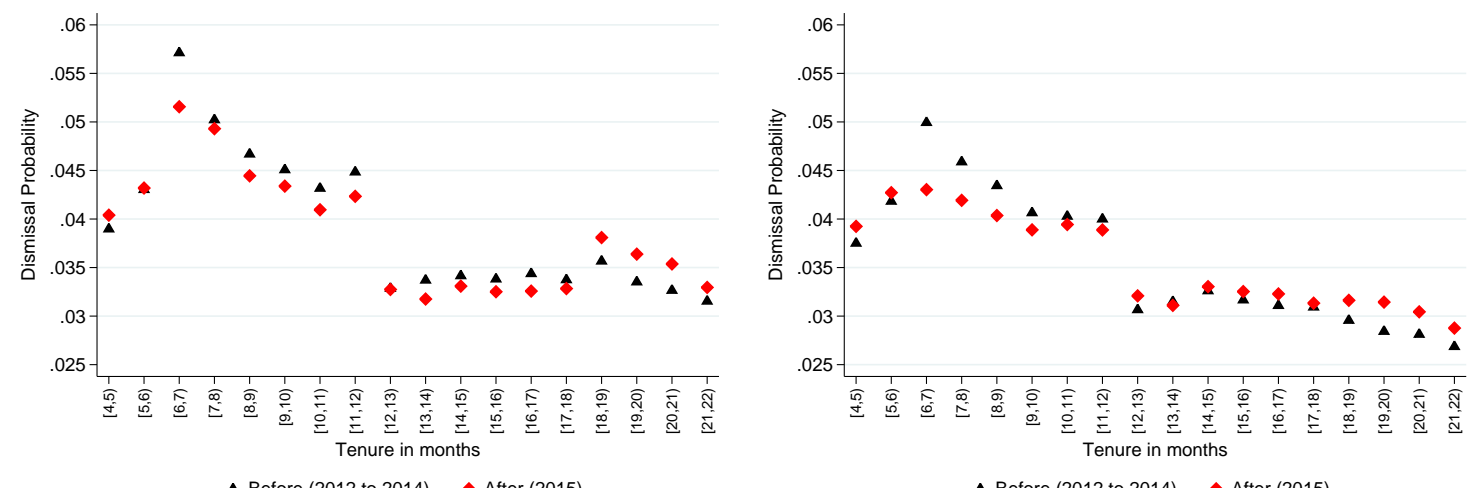

Data from Relação Anual de Informações Sociais (RAIS), 2012 to 2015. In order to account for seasonality, for each figure we include only observations for (a) March to June and (b) July to December.

Figure 2 plots average monthly dismissal probability according to job tenure before and after eligibility changes introduced by (a) MP665 and (b) Law 13.134. In order to control for seasonality and to separate the effect of MP665 and Law 13.134, we compare before (2012-2014) and after (2015) data from March to June in figure $2 \mathrm{a}$ and July to December in figure $2 \mathrm{~b}$. The average dismissal probability in figure 2a for control group [4,5) in 2012-2014 (before) is slightly below the one in 2015 (after) while it decreases significantly for the treated [6,7) over the same period. Sample (2) displays a similar pattern. Control group [18,22) experience a sizable increase while the dismissal probability of treated $[13,17)$ slightly decreases. Figure $2 \mathrm{~b}$ suggests that the effect observed in sample (1) continues when Law 13.134 is implemented. For sample (2), the dismissal probability of both treated $[13,17)$ and control group $[18,22)$ increase. Even though the increase is larger for the control group, the overall relative before-and-after treatment-control difference is smaller month in terms of UI eligibility, the treatment status for these workers is ambiguous.

${ }^{12}$ The eligibility criteria changes only apply to workers accessing UI for the first time (approximately one half of all applicants). Hence our estimates should be interpreted as measuring the intent-to-treat (ITT) effect. 
than the one observed in figure 2a. This is consistent with the fact that the eligibility changes introduced by MP665 for sample (2) are reversed by Law 13.134.

Given the institutional features of the labor market in Brazil, we specify a linear probability model for worker's dismissal that exploits the two treatment events induced by legislation changes described above. More specifically we assume that

$$
y_{i, t}=\delta_{1} \cdot M P 665_{t} \cdot T_{i}+\delta_{2} \cdot \operatorname{Law}_{t} \cdot T_{i}+\lambda \cdot T_{i}+\mu_{t}+\gamma \cdot T_{i} \cdot \text { Mont }_{t}+\tau \cdot T_{i} \cdot t+\beta \cdot X_{i, t}+\varepsilon_{i, t}
$$

where $y_{i, t}$ is an indicator variable for whether worker $i$ is unjustifiably dismissed in month $t \in\{1, \ldots, 48\}, M P 665_{t}$ takes value 1 for March-June, 2015, and Law takes value 1 for July-December, 2015, and 0 otherwise. $\mu_{t}$ is a vector of 48 month-year fixed-effects that controls for macroeconomic fluctuations that affect all workers. $T_{i} \cdot$ Mont $_{t}$ accounts for within-year group-specific seasonality where Month $_{t} \in\{J a n, \ldots, D e c\}$ and $T_{i} \cdot t$ represents group-specific linear time trends across the period. Individual controls $X_{i, t}$ include age, education level, gender, race, state fixed-effects, occupation, firm sector, contractual hours and establishment size. Treatment dummy $T_{i}$ is defined as:

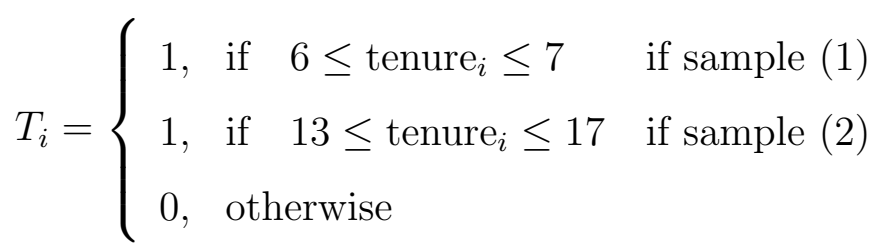

We estimate variations of equation (1) separately for samples (1) and (2). Our parameters of interest are $\delta_{1}$ and $\delta_{2}$ that capture the effects of changes in UI eligibility criteria introduced by MP665 and Law 13.134, respectively.

\section{Results}

It is key to our identification strategy that treatment and control groups exhibit average dismissal rates across time in a parallel manner during the pre-treatment period. Figure 3a plots average monthly dismissal rates for treated and control groups in sample (1). Three features stand out. First, the treated are more likely to be laid off across the sample span. Second, the dismissal rates of both groups co-move across the months before the enactment of MP665. Third, the probability 
of layoffs decreases visibly for treated groups relative to control after the MP665. Similarly, figure $3 \mathrm{~b}$ plots the corresponding monthly averages for sample (2). The dismissal rates of both treatment and control groups typically overlap closely in the first half of each year while the treated display higher rates in the second half. Interestingly, dismissal rates for the treated fall significantly below the control in the months after the enactment of MP665, only to go back to the same level relative to the control group after the approval of Law 13.134. This is consistent with the fact that the eligibility changes introduced by MP665 for sample (2) are reversed by Law 13.134.

Figure 3: Average Unjustified Dismissal Rates Over Time

(a) Sample 1

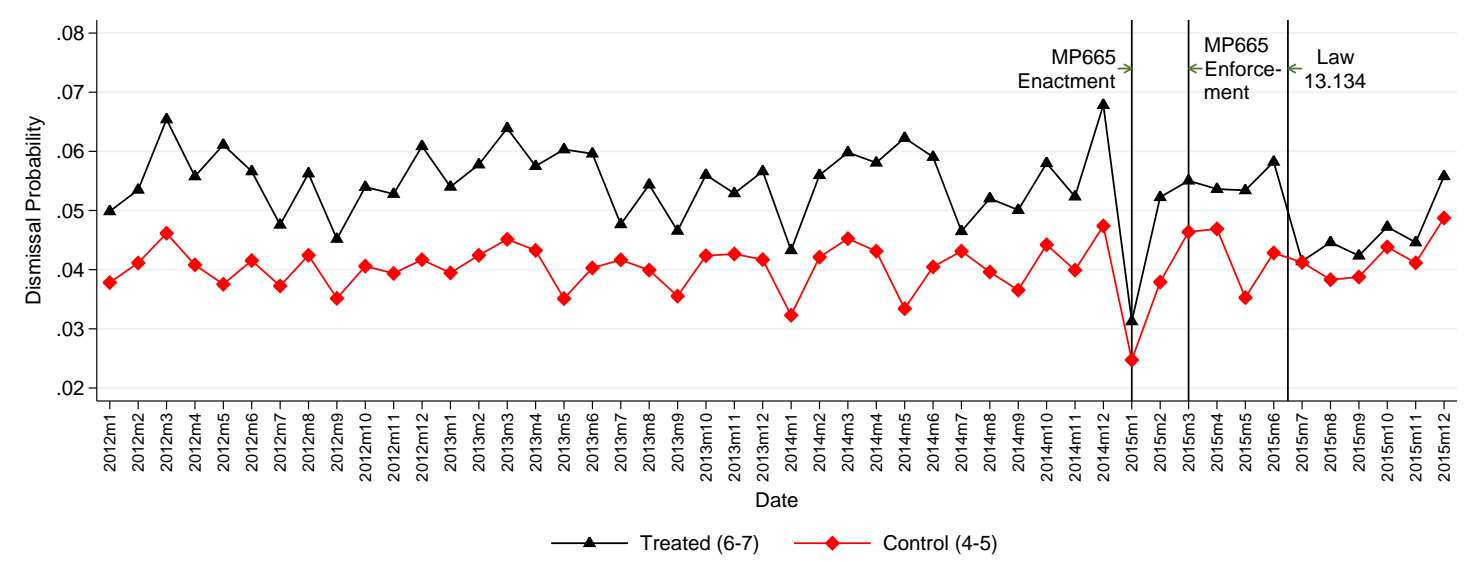

(b) Sample 2

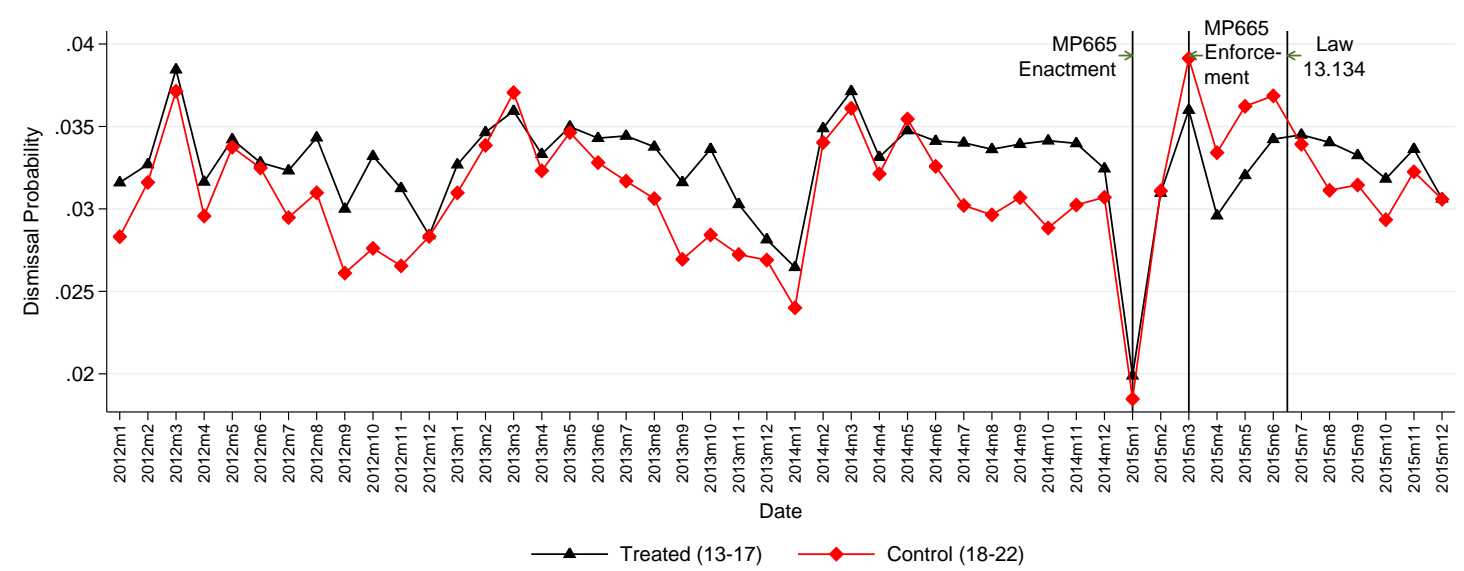

Data from Relação Anual de Informações Sociais (RAIS), 2012 to 2015. Average monthly dismissal rates for the treatment (6-7) and control (4-5) in sample (1) are plotted in (a). Corresponding monthly averages for the treatment $(13-17)$ and control (18-22) in sample (2) are reported in (b).

Table 2 reports coefficient estimates of equation (1) for sample (1) in Panel A and sample (2) in Panel B. Columns (1)-(4) sequentially include time fixed-effects, 
group specific seasonality dummies, individual covariates and group-specific time trends. For sample (1), the UI eligibility restriction introduced by MP665 relatively decreases by 0.65p.p. the probability of unjustified dismissal for workers who were eligible and became non-eligible according to the specification in column (4). The estimated effect corresponds to approximately $13 \%$ of the average monthly dismissal rate for the treated before treatment (5.4\%). Moreover, the relative decrease does not change significantly after the approval of Law 13.134 across specifications (2)(4). Estimates in column (1) indicate that results are somewhat sensitive to the inclusion of group-specific seasonality controls.

Panel B shows that MP665 also had a negative impact on dismissal rates for the treated in sample (2). The specification in column (4) exhibits an estimated effect of 0.36p.p. that corresponds to a decrease of $11 \%$ in the pre-treatment average monthly dismissal rate (3.2\%). Although the eligibility changes introduced by MP665 for sample (2) are reversed by Law 13.134, the estimated effect of MP665 does not fade away completely and remains around 0.18 p.p. or $5.5 \%$ of the average.

Table 2: Unemployment Insurance Effect on Unjustified Dismissals

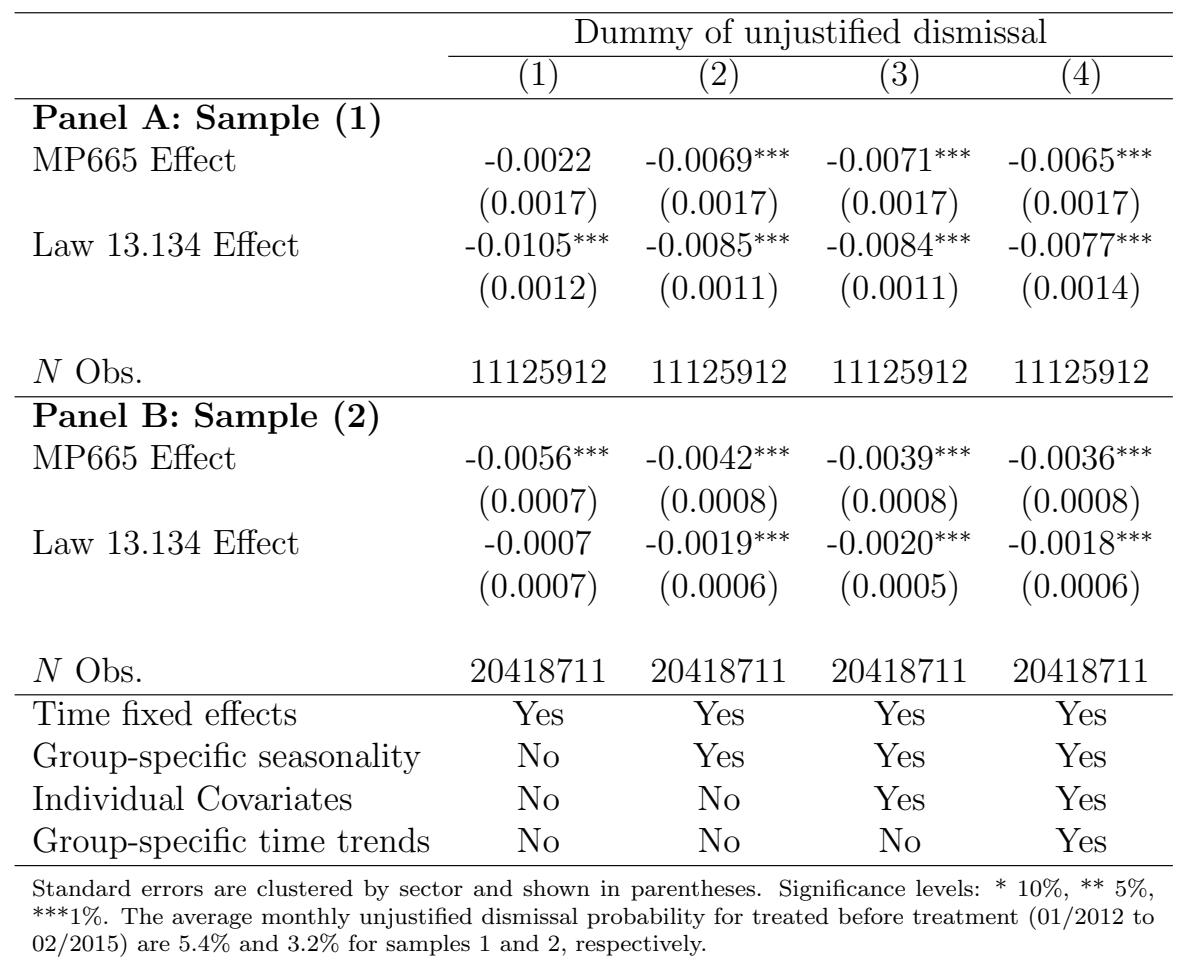

Figure 4 further illustrates the effects reported above. Using specification (4), we re-estimate a variation of the model by interacting the treatment indicator with 12 bimonthly dummy variables for 2014 and 2015. Dismissal rates do not differ 
significantly between treatment and control groups in any month before treatment in either sample. This is akin to a typical test of parallel trends as required by the difference-in-difference identification strategy. Consistent with the results reported in table 2, figure 4a show that the enactment of MP665 in March, 2015, decreases dismissal rates for the treated in sample (1) and the effect does not change significantly after the approval of Law 13.134 in July, 2015. For sample (2), the estimated effect of MP665 noticeably decreases after July, 2015, as shown in figure 4b.

Figure 4: Effect of UI Eligibility Changes Over Time

(a) Sample 1

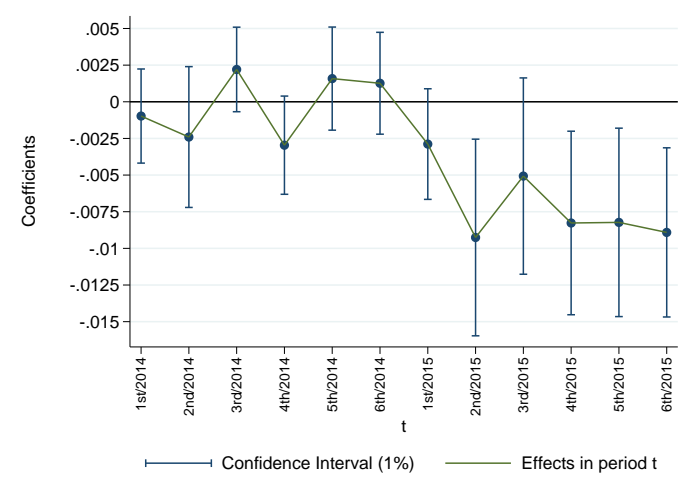

(b) Sample 2

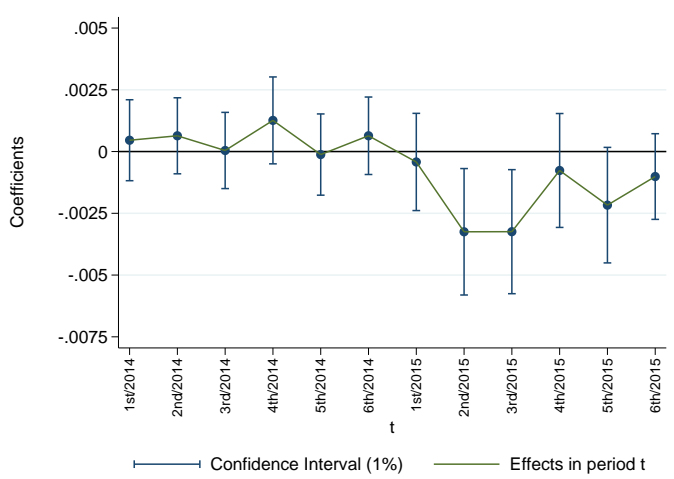

Each dot represents an interaction between 12 bimonthly dummy variables for 2014 and 2015 and the treatment indicator for (a) sample 1 and (b) sample 2 .

We have also performed a heterogeneity analysis of the baseline results. We find that the estimated effects are greater for workers in small firms, with low education and in their first job. Using a similar empirical strategy, complementary evidence using labor force survey data from Pesquisa Mensal de Emprego (PME) shows that approximately one third of workers that strategically enter UI are hired in the informal sector in the subsequent month. ${ }^{13}$

\section{Conclusion}

This paper estimates the causal effect of unemployment insurance eligibility on layoffs. We take advantage of a recent reform in Brazil that introduced more stringent eligibility criteria. We find that UI accounts for $11-13 \%$ of average pretreatment probability of dismissal. Our estimates are consistent with workers having

\footnotetext{
${ }^{13}$ Results are available upon request.
} 
the incentive to strategically induce their dismissals in order to collect UI benefits in addition to redundancy pay. 


\section{References}

Barros, Ricardo P., Corseuil, Carlos Henrique, and Foguel, Miguel (2000). "Os incentivos adversos e a focalização dos programas de proteção ao trabalhador no Brasil". Planejamento e Políticas Públicas 22, pp. 3-45.

Chetty, Raj and Finkelstein, Amy (2013). "Social insurance: connecting theory to data". In: Handbook of Public Economics. Ed. by Alan J. Auerbach, Raj Chetty, Martin Feldstein, and Emmanuel Saez. Vol. 5. Elsevier, pp. 111-193.

Gerard, François and Gonzaga, Gustavo (2016). Informal labor and the efficiency cost of social programs: evidence from the Brazilian unemployment insurance program. NBER Working Paper 22608.

Gerard, François, Rokkanen, Miikka, and Rothe, Christoph (2016). Bounds on treatment effects in regression discontinuity designs under manipulation of the running variable, with an application to unemployment insurance in Brazil. Mimeo, Columbia University.

Gonzaga, Gustavo, Maloney, William F., and Mizala, Alejandra (2003). "Labor turnover and labor legislation in Brazil". Economía 4(1), pp. 165-222.

Mortensen, Dale T (1977). "Unemployment insurance and job search decisions". ILR Review 30(4), pp. 505-517.

World Bank (2002). Policy Briefing: Brazil Job Reports. Washington, DC: World Bank. 